\title{
Recent advances in the applications of Wittig reaction in the total synthesis of natural products containing lactone, pyrone, and lactam as a scaffold
}

\author{
Heravi, M.M. , Ghanbarian, M., Zadsirjan, V., Alimadadi Jani, B. \\ Department of Chemistry, School of Science, Alzahra University, Vanak, Tehran, Iran
}

\begin{abstract}
The Wittig reaction enables the synthesis of an alkene from the reaction of an aldehyde or ketone with the ylide generated from a phosphonium salt. Undoubtedly, its usefulness in the synthesis of alkenes in an anticipated manner has resulted in the introduction of an attractive principle in synthetic organic chemistry, particularly in the total synthesis of natural products. In this review, we try to highlight the applications of Wittig reaction in total synthesis of natural products. Worthy to mention that due to the vast numbers of related achievements, described in chemical literature, we had to limit ourselves to the applications of Wittig reaction to the total synthesis of natural products that contain lactone, pyrone, or lactam as scaffold in their complex structures.
\end{abstract}

Keywords: Carbon-carbon bond, Lactam, Lactone, Natural products, Pyrone, Wittig reaction 